this leads to errors: $\varepsilon_{1}=0.027$ A. $; \varepsilon_{2}=0.008$ A.; $\varepsilon_{3}=0.002_{7}$ A. Hence the three dimensional series is seen to be greatly superior in this respect.

Nuffield Research Laboratory,

A. D. Bоотн.

Birkbeck College,

London.

1 Booth, Nature, 156, 51 (1945).

Booth, Proc. Roy. Soc., in the press.

Bragg and West, Phil. Mag., 10, 823 (1930)

- van Reigen, Physica, 9, 461 (1942).

\section{Crystal Structure of Sodium Nitroprusside}

Sodrom nitroprusside, $\mathrm{Na}_{2} \mathrm{Fe}(\mathrm{CN})_{5} \mathrm{NO} .2 \mathrm{H}_{2} \mathrm{O}$, erystallizes in the bipyramidal class $D_{2 h}$ or $\mathrm{mmm}$ (di-digonal equatorial or holoaxial) of the orthorhombic system. The forms exhibited are the $\{110\}$ primary rhombic prism, the $\{010\}$ brachy-pinakoid and the $\{011\}$ primary brachy-domal prism. The crystals are needle-like in habit along the $c$-axis and the unit cell dimensions determined from rotation photographs are: $a=11.8 \mathrm{~A} . ; b=15.52 \mathrm{~A}$. : $c=6.22 \mathrm{~A}$

Absent spectra indicate two $n$ glides of components $\left(\frac{a}{2}+\frac{b}{2}\right)$ and $\left(\frac{b}{2}+\frac{c}{2}\right)$ and the space group is $D_{2 \hbar}^{12}$ or $P_{n m n}$ with four molecules per unit cell.

Research Station,

P. W. COOKE.

Anglo-Iranian Oil Co., Ltd.

Chertsey Road,

Jan. 21.

Decomposition of Martensitic Steel Above and Below $300^{\circ} \mathrm{C}$.

DURING the course of an investigation concerning metallurgical structures employing both the electron mieroscope and electron diffraction reflexion methods, some interesting, and perhaps important results were obtained with a plain carbon steel. The literature dealing with the tempering of martensite at low temperatures generally assumes that the decomposition below $300^{\circ} \mathrm{C}$. produces a very highly dispersed carbide phase ${ }^{1}$. It was generally concluded that the carbide particles are so small and are sufficiently deformed by stresses set up during precipitation that a satisfactory $\mathrm{X}$-ray pattern could not be expected.

Electron diffraction reflexion patterns from etched surfaces of a plain carbon steel $(0.9$ per cent $\mathrm{C}, 0.15$ per cent $\mathrm{Si}$ ) clearly indicate that martensite aged at $200^{\circ} \mathrm{C}$. produces a fine dispersion of hexagonal $\mathrm{Fe}_{3} \mathrm{~N}$ as a reaction product with no trace of $\mathrm{Fe}_{3} \mathrm{C}$. Above $300^{\circ} \mathrm{C}$. the reaction product is found to be $\mathrm{Fe}_{3} \mathrm{C}$, as previously concluded from X-ray studies. Further, a specimen aged first at $200^{\circ} \mathrm{C}$. to produce highly dispersed $\mathrm{Fe}_{8} \mathrm{~N}$ will, upon heating at $350^{\circ} \mathrm{C}$., become transformed to $\mathrm{Fe}_{3} \mathrm{C}$. After half an hour at $350^{\circ} \mathrm{C}$., the pattern indicates the presence of both $\mathrm{Fe}_{3} \mathrm{~N}$ and $\mathrm{Fe}_{3} \mathrm{C}$. It appears that at low temperatures $\mathrm{Fe}_{3} \mathrm{~N}$ is the stable product, while above $300^{\circ} \mathrm{C}$., $\mathrm{Fe}_{3} \mathrm{C}$ is the equilibrium product. A nitrogen analysis of the samples gave 0.0056 per cent $\mathrm{N}$.

The data are too meagre for any conclusions as to mechanism, but it is of interest to speculate on the decomposition reactions. The following sequence of reactions is offered as a possible mechanism.

$$
\text { 1. } \begin{array}{r}
\overbrace{\mathrm{Fe}+\mathrm{C}_{\text {soln. }}+\mathrm{N}_{\text {soln. }} .}^{\text {Martensite }} \\
\stackrel{200^{\circ} \mathrm{C} .}{\longrightarrow} \mathrm{Fe}_{3} \mathrm{~N}+\mathrm{C}_{\text {soln }} . \\
\stackrel{200^{\circ} \mathrm{C} .}{\longrightarrow} \mathrm{Fe}_{3}(\mathrm{CN})+\mathrm{C}_{\text {soln }} .
\end{array}
$$$$
\text { Martensite }
$$

2. $\overbrace{\mathrm{Fe}}+\mathrm{C}_{\text {soln. }}+\mathrm{N}_{\text {soln. }} \stackrel{400^{\circ} \mathrm{C} .}{\longrightarrow} \mathrm{Fe}_{3} \mathrm{C}+\mathrm{N}_{\text {soln }}$

3. $\mathrm{Fe}_{3} \mathrm{~N}+\mathrm{C}_{\text {soln. }} \stackrel{350^{\circ} \mathrm{C} .}{\longrightarrow} \mathrm{Fe}_{3} \mathrm{C}+\mathrm{N}_{\text {soln }}$.

$$
\text { or }
$$

$$
\mathrm{Fe}_{3}(\mathrm{CN})+\mathrm{C}_{\text {soln. }} \stackrel{350^{\circ} \mathrm{C} .}{\longrightarrow} \mathrm{Fe}_{3} \mathrm{C}+\mathrm{N}_{\text {soln }} .
$$

The determination of speciflc rates and activation energies is possible by means of electron diffraction and will be essential in understanding the decomposition.

The surface preparation of the samples which produced satisfactory results was briefly as follows: (1) specimen abraded through 4/0 metallographic paper; (2) electrolytically polished; (3) etched 60-90 metallographic paper ; (2) electrolytically polished; (3) etched $60-90$ chloride in methanol ; (4) rinsed in the following sequence of solutions :
(a) 50:50 acetone-methanol plus 0.5 per cent formic acid ; $($ b $) 50: 50$ (a) $50: 50$ acetone-methanol plus 0.5 per cent formic acid ; $(b) 50: 50$
acetone-methanol ; $(c)$ dry benzene. (5) dried in blast of clean, dry air. The surfaces so produced are sufficiently clean to vield good electron The surfaces so produced are sufficiently clean to yield
diffraction patterns and electron microscope pictures.

The patterns were taken with a camera employing a $75 \mathrm{~cm}$. platespecimen distance and using $40 \mathrm{kV}$. electrons. Measurements from the patterns as compared to $X$-ray powder results make the identificaion quite certain.

The first results indicate that the use of electron diffraction may greatly aid in investigating metallurgical transformations where very
small quantities of the reaction products are concerned. It is hoped that a thorough study of the transformations in steel will be made by these methods. It appears that thoroughly degassed metal should

make a suitable starting point for an investigation.
A fuller account of this work will be published elsewhere.

R. D. HEIDENREICH.

L. STURKEY.

Dow Chemical Co. Midland,

Michigan.

sept. 6.

Barrett, C. S., "Structure of Metals" (McGraw-Hill, New York, 1943), 479.

\section{Molecular Weight and Polydispersity of Rubber by Diffusion} Measurements

THE study of diffusion in solutions of natural rubber (light crepe) by Lamm's ${ }^{1}$ method showed that even with a concentration of 0.1 per cent the normalized experimental diffusion curves diverge from the ideal Gaussian curve (Fig. 1), being characterized by a marked asymmetry and an excess of the maximal ordinate. It follows from an analysis of the experimental curves by the method of moments (up to moments of the fourth order) that they belong to Type IV Pearson curves, that is, to asymmetrical distribution curves with asymptotic branches. The determination of the perturbation multiplier enables us to calculate the course of the experimental curves with a fair degree of accuracy. The physical cause of asymmetry of the diffusion curves is the difference in the rate of diffusion to both sides of the interface (of the polymer into the solvent and back) due to a marked intermolecular interaction in the solution of the polymer at a given concentration. With a de. crease of the concentration or of the molecular weight of the dissolved substance, the asymmetry of the diffusion curves becomes less pronounced.' However, this asymmetry does not preclude the computation of the average diffusion coefficient $D$ from the standard deviation of the curve. It can indeed be shown that the probable error does not exceed 1 per cent. The average value found for natural rubber in carbon tetrachloride is $D_{20^{\circ}}=0.71 \times 10^{-7} \mathrm{~cm}^{2} / \mathrm{sec}$.
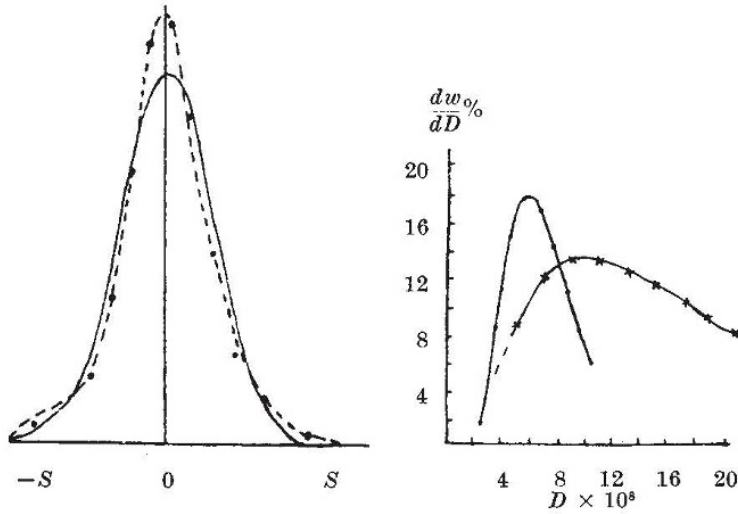

Fig. 1. Gaussian curve (full

(broken line); calculated points (dots).

Fig. 2. Curves for natura rubber (dots) and natural rubber after thermal de struction (crosses).

The asymmetry of the rubber molecules was calculated from the viscosity of rubber solutions by Simha's equation ${ }^{2}$. the applicability of which for the computation of the ratio $(b / a)$ of even highly asymmetrical particles with $b / a=70-90$ has been veriffed experimentally with nitrocellulose ${ }^{3}$. The flexibility of the rubber molecules is here of no particular significance, as under the conditions of the experiment the forces of flow are below the critical value necessary for the deformation of the molecular coil ${ }^{4}$. Computation shows that for natural rubber $(b / a)=117-120$ and $\left(f / f_{0}\right)=4 \cdot 35-4 \cdot 40$. By combining the values of $D$ and $\left(f / f_{0}\right)$ by Polson's method ${ }^{5}$, we find that at a concentration of 0.116 per cent the molecular weight of natural rubber is $M=830,000$. Lansing and Kraemer's flgure obtained ${ }^{6}$ by the ultracentrifugation method for a 0.05 per cent solution is $M$ is $400,000-435,000$. In both cases there undoubtedly occurs aggregation in the solution. Extrapolation of these results to $G=0$ gives $M$ equal to $130,000-150,000$, which is presumably the true molecular weight of natural rubber. which is presumably the true molecular weight of natural rubber.
Figures very close to this were obtained for natural rubber twice Figures very close to this were obtained for natural rubber twice
precipitated from a carbon tetrachloride solution by excess of alcohol, precipitated from a carbon tetrachloride solution by excess of alcohol,
namely, $D_{20^{\circ}}=0.66 \times 10^{-7} \mathrm{~cm} . / \mathrm{sec} ; \quad b / a=123 ; \quad f / f_{0}=4.45$
$M=970,000$ (at a concentration $0 \cdot 135$ per cent). After thermal $M=970,000$ (at a concentration $0 \cdot 135$ per cent). After thermal
destruction of rubber caused by exposure for three hours to $140^{\circ}$ in air the molecular characteristics changed abruptly: $D_{20^{\circ}}=1.6 \times 10^{-7}$ air the molecular characteristics changed abruptly: $D_{20^{\circ}}=1.6 \times 10^{-7}$
$\mathrm{~cm} .2 / \mathrm{sec}$; b/a $=88 ; \mathrm{f} / \mathrm{f}_{0}=3.85 ; \boldsymbol{M}=103,000$ (for a 0.135 per

The following are the figures obtained for an industrial specimen of divinyl synthetic rubber : $D_{20^{\circ}}=2 \cdot 1 \times 10^{-7} \mathrm{~cm}^{2} / \mathrm{sec}$; $b / a=65$; flf $f_{0}=3 \cdot 31 ; M=73,000$ (for a $0 \cdot 112$ per cent solution); the normalized fifusion curve has in this case a quite symmetrical character

A comparison with the results of calculation of $M$ from Staudinger's equation $\left(\boldsymbol{K}_{m}^{\text {carb. tetrachl. }}=3 \times 10^{-4}\right)$ showed that at $\boldsymbol{M} \sim 100,000$ and less this equation gives good agreement with $M$, whereas with $M \sim$ 